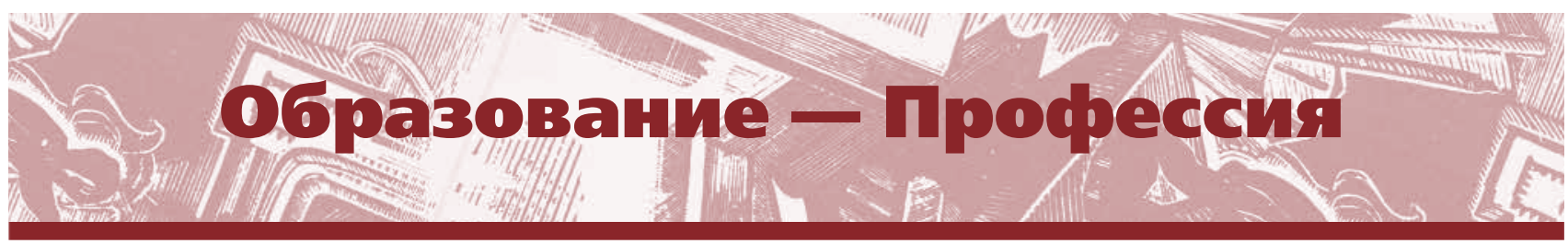

УДК 330.163.14:021

ББК $65.497 .8+78.370$

\title{
С.М. Каранец
}

\section{Характеристика библиотечных услуг как общественных благ}

Одним из актуальных вопросов, активно обсуждаемых на международных и всероссийских конференциях, является определение экономической сущности основных категорий, связанных с библиотечным обслуживанием. В статье рассмотрена экономическая природа библиотечных услуг как общественных благ, классификация библиотечных услуг (по степени конкурентности потребления и принципа исключаемости; по уровню использования информационно-коммуникационных технологий; по форме собственности производителя), показана активная деятельность публичных библиотек на рынке товаров и услуг как реальных конкурентов частным предпринимателям, оказывающим рыночные услуги. В статье рассмотрен процесс диверсификации, проникновения на российский рынок библиотечных услуг издателей, архивов и других организаций путем создания ими чистых общественных благ. Особое внимание уделено благам, которые временно не относятся к чистым общественным благам.

Ключевые слова: блага, общественные блага, локальные и глобальные общественные блага, РНБ.

Для цитирования: Каранец С.M. Характеристика библиотечных услуг как общественных благ // Библиотековедение. 2016. Т. 1. № 2. С. 227-234.

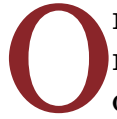
пределение экономической сущности основных категорий, связанных с библиотечным обслуживанием, является одним из актуальных и проблемных вопросов, активно обсуждаемых на всероссийских конференциях, проводимых в Российской национальной библиотеке (РНБ). Выступая на Международной научно-практической конференции «Инвестиции в библиотечном деле: опыт, проблемы, перспективы» еще в 2006 г., доктор экономических наук Ю.А. Горшков (19552010) предложил в структуре совокупного спроса на культурные блага обособить спрос на библиотечное благо. Создание системного видения ключевого направления этической экономии библиотечного дела он видел в критическом анализе подходов к характеристике библиотечных услуг как общественных благ [1].

Сам термин «общественное благо» (public good) был использован Нобелевским лауреатом П.Э. Самуэльсоном в 1954 г. для характеристики товаров, потребление которых одним лицом не приводит к уменьшению потребления другими лицами. Такие блага доступны домохозяйствам вне зависимости от возраста, пола, социального статуса и т. д. Общественные блага можно проклассифицировать, используя принцип неконкурентности потребления (non-rivalous) и принцип неисключения (non-

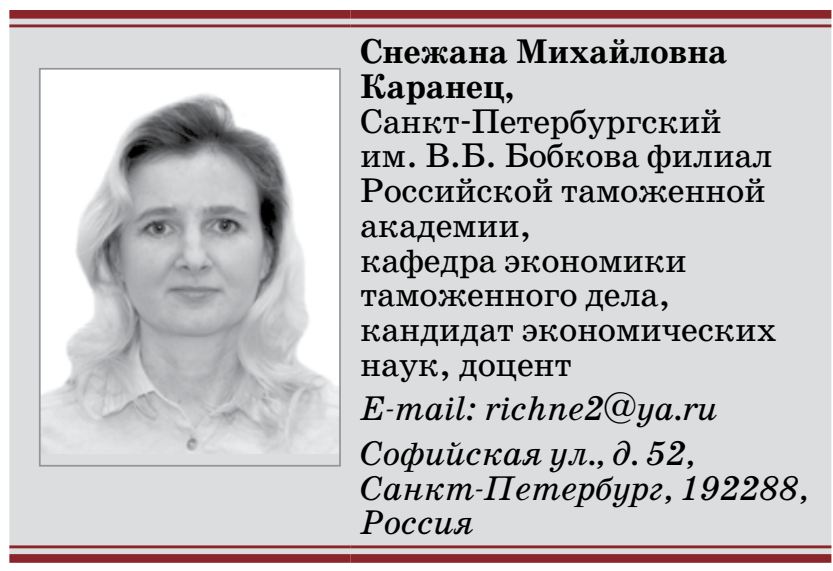

exclusion principle). Их принято подразделять на подтипы - чистые общественные блага и квазиобщественные блага.

Актуальность деления библиотечных услуг по двум принципам (соперничества и исключаемости) связана с тем, что на совокупный читательский спрос частных и общественных библиотечных благ влияют различные неценовые детерминанты. Несмотря на то что потребление культурных благ, в том числе библиотечных, связано с положительным внешним эффектом, сфера действия закона спроса и закона предложения различна. Законы рынка работают только по от- 
ношению к частным благам, но перестают действовать в отношении чистых общественных благ.

\section{Чистые общественные блага}

Чистые общественные блага (pure public goods)* обладают свойствами: а) неисключения, неделимости; б) неконкурентности (несоперничества) в потреблении. Классическим примером чистого общественного культурного блага является композиция из десяти скульптур, украшающая вход в Российскую национальную библиотеку (РНБ) Санкт-Петербурга. Доступ к композиции открыт всем без исключения. Невозможно исключить лиц, не являющихся читателями библиотеки, получающих эстетическое удовольствие от просмотра такого блага. Особой популярностью композиция пользуется у молодоженов и их гостей в день свадьбы.

В условиях, когда активно внедряются информационно-коммуникационные технологии (ИКТ), расширяется спектр предоставляемых общественных услуг публичными библиотеками. В настоящее время все чистые общественные библиотечные блага можно подразделить на группы:

- локальные, т. е. без использования ИКТ, в том числе Интернета. Для организации процесса потребления таких благ необходимо присутствие домохозяйства в месте расположения, например, скульптурной композиции. Если публичное мероприятие проводится один раз в год, скажем, участие РНБ в акции «Библионочь - 2015», то необходимо не только присутствие в определенном месте, но и в строго определенное время;

- глобальные (международные), т. е. блага, потребление которых всем народонаселением невозможно без использования ИКТ. Данные блага доступны для пользователей вне зависимости от места их оказания (производства, создания) и места нахождения потребителя. Процесс потребления глобальных общественных благ напрямую зависит от обеспеченности домохозяйств и учреждений культуры ПК, подключенных к Интернету.

К глобальным чистым общественным благам, основанным на активном использовании ИКТ, можно отнести электронную коллекцию авторефератов диссертаций на соискание ученой степени доктора (кандидата) наук, находящуюся в свободном доступе, размещенную на сайте ЭБ Российской государственной библиотеки (РГБ) (табл. 1, последний пункт 3 колонки).

Другим примером глобального общественного блага является онлайн-трансляция Ежегодного совещания директоров федеральных и централь-

таблица 1

Типы экономических благ на примере отрасли «культура и искусство»

\begin{tabular}{|c|c|c|}
\hline $\begin{array}{l}\text { По исключаемости } \\
\text { По степени } \\
\text { соперничества, } \\
\text { конкурентности }\end{array}$ & $\begin{array}{c}\text { Принцип исключения } \\
\text { (платный доступ к товару, услуге) }\end{array}$ & $\begin{array}{l}\text { Неисключаемые из потребления } \\
\text { (бесплатность доступа), } \\
\text { общедоступность блага }\end{array}$ \\
\hline $\begin{array}{l}\text { Конкурентные в } \\
\text { потреблении } \\
\text { Процесс оказания } \\
\text { благ направлен на } \\
\text { индивидуальное } \\
\text { потребление }\end{array}$ & $\begin{array}{l}\text { Частные блага (private goods): } \\
\text { сканирование документов } \\
\text { из фондов РНБ, составление } \\
\text { библиографических списков и } \\
\text { справок по охранным документам } \\
\text { интеллектуальной собственности, } \\
\text { кино-, видео-, фотосъемка в } \\
\text { интерьерах РНБ }\end{array}$ & $\begin{array}{l}\text { Товары общего доступа, общие ресурсы } \\
\text { (common goods): } \\
\text { журнальный фонд библиотек }\end{array}$ \\
\hline $\begin{array}{l}\text { Неконкурентные в } \\
\text { потреблении } \\
\text { Неделимое благо } \\
\text { потребляется } \\
\text { коллективно (совместно) }\end{array}$ & $\begin{array}{l}\text { Клубные блага (club goods): } \\
\text { - услуги кинотеатров, частных } \\
\text { парков; } \\
\text { - групповое обучение и стажировки } \\
\text { сотрудников библиотек и частных } \\
\text { лиц на платной основе в учебном } \\
\text { центре РНБ, например обучение } \\
\text { по программе «Библиотечно- } \\
\text { информационная деятельность» } \\
\text { стоимостью } 25400 \text { руб. }\end{array}$ & $\begin{array}{l}\text { Чистые общественные блага (pure public } \\
\text { goods): } \\
\text { локальное: композиция из } 10 \text { скульптур, } \\
\text { украшающих вход в здание РНБ по } \\
\text { адресу: СПб., Московский пр., 165.; } \\
\text { глобальные: } \\
\text { - Пленарное заседание пятого } \\
\text { Всероссийского форума публичных } \\
\text { библиотек, состоявшееся } 15.12 .2015, \\
\text { транслировавшееся в Интернете; } \\
\text { - Электронная библиотека } \\
\text { авторефератов диссертаций РГБ, } \\
\text { находящихся в свободном доступе. }\end{array}$ \\
\hline
\end{tabular}

Составлено по: [2, 3].

* В отечественной научной и учебной литературе существует два варианта перевода «pure public good». Научные категории «чисто общественное благо» и «чистое общественное благо» используют как равноправные термины-синонимы. 
ных региональных библиотек, состоявшегося 20-21 октября 2015 г. в Санкт-Петербурге в здании РНБ по инициативе Министерства культуры РФ, РНБ и РГБ.

Историю предоставления общественных библиотечных благ в России можно условно разделить на три этапа.

На первом этапе оказание общественных благ было ограничено только государственным сектором экономики. Так, в совместном докладе Т.Н. Ивлиевой, Е.В. Смолиной производство общественных благ закреплено только за госпредприятиями (государственным сектором экономики) [4]. Подобные утверждения характеризуют советский период развития библиотечной деятельности. В постсоветское время в XXI в. (на втором этапе) они стали догмой. Создание и накопление электронных коллекций книг, научных журналов способствовало переходу к следующей ступени развития.

Технологическими нововведениями первого этапа являются: приобретение ПК, постепенная оцифровка карточных каталогов, открытие компьютерных залов, подключение к информационно-телекоммуникационной сети Интернет, закупка оборудования для оцифровки книг, переход на использование технологии ретроспективной конверсии, изменение технологии обслуживания читателей, связанной с заменой читательских билетов на пластиковые, накопление электронных ресурсов, создание и ведение электронных каталогов, веб-сайтов библиотек, функционирование залов электронных ресурсов.

На втором этапе небольшую, но все же конкуренцию российским библиотекам составили частные отечественные и зарубежные издательства, крупнейшие репозитории негосударственных и государственных высших учебных заведений (табл. 2).

Швейцарское издательство «S. Karger» выпускает порядка 100 журналов и 50 новых книг. $1 / 5$ часть журналов можно найти в открытом доступе. Компания Elsevier B.V. (Нидерланды), работая на платформе ScienceDirect, в открытый

Классификация основных создателей общественных благ по форме собственности

Таблица 2

\begin{tabular}{|c|c|c|c|}
\hline \multirow{3}{*}{ Показатели } & \multicolumn{3}{|c|}{ Форма собственности на средства производства } \\
\hline & \multicolumn{2}{|c|}{ Общедоступных библиотек } & $\begin{array}{c}\text { Некоторых конкурентов } \\
\text { публичных библиотек }\end{array}$ \\
\hline & Государственная & Муниципальная & $\begin{array}{c}\text { Частная } \\
\text { (негосударственная) }\end{array}$ \\
\hline 1. Вид организации & \multicolumn{2}{|c|}{ Некоммерческие организации (НКО) } & $\begin{array}{l}\text { Коммерческие организации, } \\
\text { негосударственные НКО }\end{array}$ \\
\hline $\begin{array}{l}\text { 2. Организационно- } \\
\text { правовая форма }\end{array}$ & $\begin{array}{l}\text { Федеральное государственное } \\
\text { бюджетное учреждение }\end{array}$ & $\begin{array}{l}\text { - Муниципальное } \\
\text { бюджетное учреждение } \\
\text { культуры; } \\
\text { - Казенное учреждение } \\
\text { культуры; } \\
\text { - Автономное учреждение }\end{array}$ & $\begin{array}{l}\text { ООО, АО, индивидуальное } \\
\text { предпринимательство, } \\
\text { товарищество }\end{array}$ \\
\hline 3. Заказчик & $\begin{array}{l}\text { - Правительство РФ в } \\
\text { отношении федеральных } \\
\text { бюджетных учреждений; } \\
\text { • Высший исполнительный } \\
\text { орган гос. власти субъекта } \\
\text { РФ в отношении бюджетных } \\
\text { учреждений субъекта РФ }\end{array}$ & Местная администрация & Частный предприниматель \\
\hline $\begin{array}{l}\text { 4. Финансирование } \\
\text { процесса оказания } \\
\text { общественных благ }\end{array}$ & $\begin{array}{l}\text { Финансовое обеспечение } \\
\text { выполнения библиотекой } \\
\text { гос. задания осуществляется } \\
\text { в виде субсидий из } \\
\text { федерального бюджета на } \\
\text { основании соглашения } \\
\text { о порядке и условиях } \\
\text { предоставления } \\
\text { субсидий, заключаемого с } \\
\text { Министерством культуры РФ }\end{array}$ & $\begin{array}{l}\text { Финансовое обеспечение } \\
\text { выполнения } \\
\text { муниципального } \\
\text { задания учреждением } \\
\text { осуществляется в виде } \\
\text { субсидий из бюджета, } \\
\text { например сельского } \\
\text { поселения }\end{array}$ & $\begin{array}{l}\text { Частное, без нагрузки на гос. } \\
\text { и муниципальный бюджет }\end{array}$ \\
\hline 5. Примеры & $\begin{array}{l}\text { Федеральное государственное } \\
\text { бюджетное учреждение } \\
\text { «Российская национальная } \\
\text { библиотека» }\end{array}$ & $\begin{array}{l}\text { Муниципальное } \\
\text { бюджетное учреждение } \\
\text { «Рябковская } \\
\text { поселенческая сельская } \\
\text { библиотека имени } \\
\text { Ф.Ф. Павленкова» }\end{array}$ & $\begin{array}{l}\text { OOO Elsevier, } \\
\text { C. Karger GmbH }\end{array}$ \\
\hline
\end{tabular}


доступ предоставляет 7\% от 2,6 тыс. полнотекстовых электронных журналов. В 2015 г. компания Elsevier планировала выпустить электронный журнал нового поколения для открытого доступа [5]. Удачный маркетинговый ход по предоставлению потенциальным покупателям бесплатно незначительной доли электронной коллекции направлен на расширение рынка сбыта.

Образовательные организации также активно осваивают процесс производства общественных библиотечных услуг. Репозитории открытого доступа высших учебных заведений (институциональные репозитории) представляют собой открытый интернет-архив академических, научно-исследовательских работ и методических разработок ученых вуза, ориентированных на отраслевую специализацию учебного заведения. Так, репозиторий Белорусского национального технического университета (Belarusian National Technical University Repository) разместил в открытый доступ издания ученых Республики Беларусь в области энергетики, технологий управления, робототехники, строительства и др.

На втором этапе была разработана технология ранжирования репозиториев учебных и научно-исследовательских учреждений. Во всемирном вебометрическом рейтинге (по данным на июль 2015 г.) содержится информация о 2,3 тыс. институциональных репозиториях, в том числе специализирующихся в области культуры. Бесплатный доступ к цифровому культурному наследию предоставляют Belarusian State University of Culture and Arts Repository (Республика Беларусь), European Cultural Heritage Online (ФРГ), Chinese Culture University Institutional Repository (КНР) и другие репозитории.

Российские вузы занимают в 2016 г. 224 место (Ural Federal University Institutional Repository), 772 место (E-library Udmurt State University), 698 место (Belgorod State University Repository). Замыкает вебометрический рейтинг из 21 российского вуза Repository Russian Presidential Academy of National Economy and Public Administration, который занимает 2197 место в мире по количеству веб-страниц, извлеченных из Google, числу внешних ссылок, количеству текстовых файлов (PostScript, Adobe Acrobat, MS Word и PowerPoint) и др. [6]. Репозиторий Российской академии народного хозяйства и государственной службы при Президенте Российской Федерации (РАНХиГС) позволяет бесплатно скачать отдельные статьи из журнала «Библиотековедение».

Технологическими нововведениями второго этапа являются: появление услуги удаленной записи (в РГБ с 2013 г.); открытие крупнейшими библиотеками виртуальных читальных залов в городах России, Финляндии, некоторых странах СНГ, Монголии, США и др.; массовый переход библиотек на автоматизированный учет посещаемости с помощью электронных читательских билетов; ведение учета обращений удаленных пользователей, посещаемости сервера (веб-сайта) библиотеки; активное пополнение фондов документами на нематериальных носителях, возможность просмотра виртуальных выставок; открытие круглосуточного доступа к электронному каталогу РГБ через мобильное приложение eRSL.

На третьем (современном) этапе предпринята попытка объединить разрозненные электронные коллекции частных и государственных учреждений и предоставить бесплатный доступ к библиотечным, музейным и архивным фондам.

Переход к третьему этапу в Европе стал возможен только после того, как было оцифровано порядка 10\% (или 300 млн объектов) культурного наследия стран ЕС. Выступая на 14 Международной научно-практической конференции «Электронный век культуры», исполнительный директор Europeana Foundation Дж. Казинс (Нидерланды) презентовала новый сервис «Europeana Strategy 2020», который стартовал в 2007 году. Платформа цифрового культурного наследия разместила и предоставила доступ к 45 млн элементов цифрового культурного наследия 3,5 тыс. учреждений (см. рис.). В том числе 60 тыс. объектов из России [7]. Несмотря на то что проект «Europeana Strategy 2020» финансируется Евросоюзом, министерствами культуры стран-участниц ЕС, используемая поисковая система значительно уступает поисковой

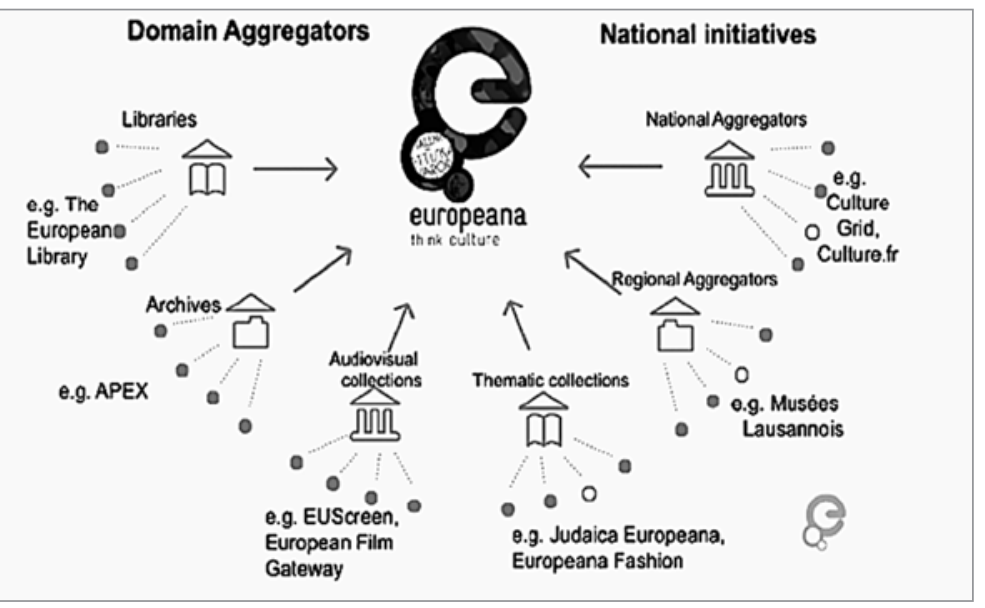

Рис. Два типа агрегаторов (партнеров) «Еигореапа Strategy 2020» [7]

системе Google, принадлежащей американской THК Google Inc., основанной в 1998 году.

Крупнейшими конкурентами веб-проекта «Europeana стратегия 2020» выступают национальные цифровые проекты (библиотеки):

- австралийский веб-архив «PANDORA», предоставляющий доступ с 1996 г. к электронным журналам, веб-сайтам научного и культурного значения, интернет-изданиям Австралии. Общий размер 369 млн файлов составил 18,5 ТБ (по данным на декабрь 2015 г.); 
• с 2013 г. расположенная в США Цифровая публичная библиотека Америки (Digital Public Library of America - DPLA), предлагающая бесплатный интерактивный доступ к фондам американских архивов, библиотек, музеев [8].

В РФ проект НЭБ начал реализовываться с 2004 г. по инициативе РГБ, РНБ как корпоративный инновационный проект. Постепенно, с присоединением ГПНТБ России, Президентской библиотеки им. Б.Н. Ельцина, АПРИКТ он изменил статус на межведомственный проект общегосударственного масштаба. В декабре 2014 г. портал начал работать в режиме бета-версии, а с июня 2015 г. - стал переводиться в режим промышленной эксплуатации.

На сайте НЭБ можно ознакомиться с каталогами изданий, которые хранятся в библиотеках России, коллекциями оцифрованных документов (высокого качества), расположенными в открытом доступе. Если пользователь НЭБ проходит процедуру полной регистрации, сканирует паспортные данные, то теоретически он получает возможность просмотреть контент, охраняемый законодательством об авторских и смежных правах.

На Международном профессиональном форуме в июне 2015 г. «Книга. Культура. Образование. Инновации» статс-секретарь - заместитель министра культуры РФ Г.П. Ивлиев представил новые статистические данные. На портале НЭБ электронных текстов расположено:

- 52 тыс. книг, оцифрованных в рамках исполнения Указа Президента РФ № 597 «О мероприятиях по реализации государственной социальной политики» (с 2012 по 2014 г.);

- 435 тыс. диссертаций и авторефератов (ресурс РГБ);

- ресурсы 35 библиотек-участниц [9].

Несмотря на то что авторы проекта НЭБ позиционируют его как бесплатный доступ к информационным ресурсам, отечественный вариант создания платформы предполагает использовать принцип финансовой заинтересованности правообладателей книг и издательств.

C одной стороны, начиная с 2014 г. Министерство культуры РФ выделяет средства на закупку (приобретение авторских прав и выполнение работ по оцифровке для включения в НЭБ) $10 \%$ издаваемых в РФ книг. Разработанная в 2013 г. методика отбора издаваемых в стране $10 \%$ наименований документов для включения в НЭБ была утверждена Министерством культуры РФ 07.10.2014 г. вместе с дорожной картой в приложениях № 3,4 «Концепции развития Национальной электронной библиотеки на 2014-2016 гг.».

C другой стороны, планируется внедрить ряд платных сервисов на сайте НЭБ, предлагающих покупку книг, в том числе «Книга на заказ». В плане (дорожной карте) развития НЭБ РФ на 2015 г. предусмотрена реализация системы биллинга и возмездных сервисов. Смещение акцента в пользу предоставления платных услуг значительно уменьшит позитивные составляющие НЭБ как общественного блага.

В условиях формирования фондов национальной электронной библиотеки (НЭБ) особое значение придается благам, которые:

а) временно не относятся к категории «общественного блага». Г.П. Ивлиев называет такие блага «условно открытый контент» [9]. Созданный в обществе институт авторского и смежного права дает нам возможность обособить такие блага в отдельную группу. С течением времени, когда, например, истек срок действия авторских прав на литературное произведение, благо автоматически переходит в группу «чисто общественных благ». Актуальность постоянного мониторинга таких благ возрастает на этапе экономического кризиса, спада экономической конъюнктуры, когда налоговые поступления в бюджет значительно сокращаются;

б) временно относятся к категории «чистого общественного блага». В Казахстане практикуется покупка годовой национальной лицензии на использование базы данных Scopus.

Важнейшими технологическими нововведениями третьего этапа являются: использование восстанавливаемого универсального идентификатора pecypca «persistent URL»; открытие виртуальной справочной службы «Спроси библиографа». В РГБ по рабочим дням организован «Чат с библиотекарем» в режиме реального времени.

Подводя краткий итог, можно отметить, что на третьем этапе произошло осознание необходимости аудита и ведения в рамках одной страны или континента полного реестра растущего цифрового контента, обеспечение единой точки доступа к фонду. Следующий этап развития будет связан с созданием библиотеки (единого окна, точки доступа), предлагающей одновременный (сквозной), интегрированный, высокоскоростной поиск по всем полнотекстовым многоязычным ресурсам открытых репозиториев мира, бесплатных рецензируемых электронных отечественных и зарубежных научных журналов. Актуальность организации такой объединенной общедоступной межконтинентальной научной цифровой библиотеки с использованием мультилингвистической поисковой системы очевидна.

Таким образом, классифицируя производителей общественных библиотечных благ по форме собственности, важно выделять не только отечественные муниципальные, государственные библиотеки, интернет-архивы, но и парабиблиотечные организации (от греческого слова «лари́» - возле, мимо, вне, около), в том числе и иностранные. Оказание общественных услуг для таких организаций не является главной целью создания и ведения бизнеса. Для частных предпринимателей, агрегаторов, институциональных репозиториев вузов это дополнительные к основ- 
ной деятельности услуги, способствующие привлечению внимания, рекламированию учебного (научного, культурного, издательского) учреждения, созданию положительного имиджа, репутации, привлечения инвестиций.

\section{Клубные и общедоступные квазиобщественные блага}

Квазиобщественные (смешанные) блага, в том числе библиотечные услуги, имеют признаки общественных благ лишь частично. Например, клубные блага (club goods) обладают свойствами исключаемости и несоперничества в потреблении. Экономическую теорию «клубных благ» описал Нобелевский лауреат по экономике Дж.М. Бьюкенен (James McGill Buchanan) в работе "An Economic Theory Of Clubs» в 1965 году.

В отрасли «культура и искусство»к клубным благам относят услуги театров, кинотеатров, частных парков. Для того чтобы попасть в здание театра, необходимо заплатить за входной билет (принцип исключаемости). Спектакль доступен для всех зрителей в кинотеатре (несоперничество в потреблении). Услуги частных библиотек также можно отнести к клубным благам. Для того чтобы войти в библиотеку, нужно зарегистрироваться, получить читательский билет (библиотечную карточку), заплатить членский взнос (принцип исключаемости). Например, в декабре 2015 г. индивидуальный членский взнос в Лондонской библиотеке (London Library) составлял $£ 485$ в год (по £40,41 в месяц) [10].

Другой подвид квазиобщественного блага принято называть «common goods», что дословно означает «общедоступное благо», обладающее свойствами неисключаемости и соперничества. Генеральный директор Российской национальной библиотеки А.В. Лихоманов, освещая историю развития РНБ на Ежегодном совещании руководителей федеральных и центральных региональных библиотек России, особо выделил уникальное переменное свойство таких квазиобщественных благ. В 1960-х гг. в РНБ спрос на услуги читальных залов значительно превышал их пропускную способность. В истории развития библиотеки можно выделить периоды, когда наблюдались большие очереди. Исторический пример, приведенный А.В. Лихомановым, проиллюстрировал тот факт, что услуги библиотек относятся к категории легко перегружаемых благ.

Для того чтобы они были доступны любому жителю страны, необходимо создавать сеть библиотек, территориально приближенных к месту жительства домохозяйств. Политика, направленная на оптимизацию, ликвидацию одних и укрупнение других библиотек, приводит либо к росту нагрузки на оставшиеся библиотеки (если они расположены в пешеходной доступности), либо к отказу от библиотечных услуг (если доступ- ность транспортная, а региональная дорожная инфраструктура находится в неудовлетворительном состоянии).

\section{Частные блага}

Новым явлением в постсоветский период для общедоступных библиотек стало предоставление широкого ассортимента платных услуг, направленных на извлечение прибыли. Информация о том, что только частные предприятия участвуют в создании рыночных благ, значительно устарела. Современные публичные библиотеки на рынке товаров и услуг выступают как конкуренты частным предпринимателям. Так, цены на услуги ксерокопирования в РНБ совпадают с рыночными. Они соответствуют расценкам частных книжных (канцелярских) магазинов города, а по ряду позиций даже превышают их. Однако цели предоставления таких услуг различны. Если публичные библиотеки оказывают платные услуги как дополнительные, с целью сохранить постоянный поток читателей, снизить заполняемость читальных залов, избежать очередей, ажиотажного спроса, сократить время нахождения читателя в библиотеке, увеличив их свободное время, то целью коммерческих предпринимателей является максимизация прибыли.

Второе отличие связано с ограничениями, которые имеют все некоммерческие организации. Библиотеки не могут «оказывать услуги, которые не установлены Уставом, государственным заданием и ведомственным перечнем» [11]. Важно отметить и третью отличительную особенность. Публичные библиотеки стараются строго соблюдать Гражданский кодекс РФ. Они работают только на легальном рынке. В РГБ разрешается копировать до 15\% научной статьи или книги. Полная распечатка текста, являющегося объектом авторского права, запрещена. У читателей появляется возможность получить электронную копию публикации, если она перестала быть защищенной авторским правом, перешла в общественное достояние.

Таким образом, современные общедоступные библиотеки предлагают жителям РФ весь спектр культурных экономических благ: общественных, квазиобщественных и не относящихся к основной деятельности частных благ. Обогащение ассортимента библиотечных услуг частными благами позволило сократить время оказания общественных благ, значительно снизить аудиторную нагрузку читальных залов. С постепенным внедрением новейших информационных технологий ассортимент предоставляемых общественных благ значительно расширился, появилась небольшая конкуренция со стороны не относящихся к публичным библиотекам парабиблиотечных учреждений. Затягивание решения проблемы доступности глобальных общественных благ во многом связано с низкой степенью компьютеризации и 
интернетизации российских домохозяйств и бюджетных организаций культуры. В постсоветский период развития библиотечного дела наблюдается процесс диверсификации, взаимопроникновения частного и государственного производства.

\section{Список источников}

1. Горшков Ю.А. Этика финансирования ресурсной модернизации российских библиотек [Электронный peсурс] // Официальный сайт Междунар. науч.практ. конф. «Инвестиции в библиотечном деле: опыт, проблемы, перспективы». URL: http://www. nlr.ru/tus/161006/ (дата обращения: 16.12.2015).

2. Электронная библиотека диссертаций [Электронный ресурс] / Poc. гос. б-ка. URL: http://diss.rsl.ru (дата обращения: 16.12.2015).

3. Прейскурант № 6/15 дополнительных услуг РНБ. Утвержден Приказом генерального директора РНБ от 14 августа 2015 г. № 305 [Электронный ресурс] // Официальный сайт РНБ. URL: http://www.nlr. $\mathrm{ru} / \mathrm{nlr} /$ docs/price_gen/prices.pdf (дата обращения: 16.12.2015).

4. Ивлиева Т.Н, Слолина Е.В. Государственное инвестирование в социокультурную сферу [Электронный peсурс] // Официальный сайт Междунар. науч.практ. конф. «Инвестиции в библиотечном деле: опыт, проблемы, перспективы». URL: http://www. nlr.ru/tus/161006/Ivlieva_Smolina.htm (дата обращения: 16.12.2015).

5. Каранец C.M. Фонды библиотек в цифровую эпоху: традиционные и электронные ресурсы, ком- плектование, использование. Обзор материалов V Bсеросс. науч.-практ. конф. // Ученые записки Санкт-Петербургского филиала РТА. 2015. № 2(54). C. 247-256.

6. The Ranking Web of World repositories [Электронный pecypc] // Official website. URL: http://repositories.webometrics.info/en/About_Us (дата обращения: 17.12.2015).

7. Cousins J. Europeana Strategy 2020 - Making it work for the users and the data providers [Стратегия 2020 Europeana - ориентация на пользователей и провайдеров контента] [Электронный ресурс] // Официальный сайт Российской ассоциации электронных библиотек. URL: http://www.aselibrary.ru/video/conference43/conference436708/ (дата обращения: 07.02.2016).

8. Website PANDORA: Australia's Web Archive [Электронный ресурс] // Official website. URL: http:// pandora.nla.gov.au/statistics.html (дата обращения: 11.02.2016).

9. Ивлиев Г.П. Национальная электронная библиотека - 2014/2015 [Электронный ресурс] // Официальный сайт Российской ассоциации электронных библиотек. URL: http://www.aselibrary.ru/video/ conference43/conference436448/ (дата обращения: 11.02.2016).

10. London Library [Электронный ресурс] // Website: URL: http://www.londonlibrary.co.uk/ (дата обращения: 06.12.2015).

11. Website Accounts Chamber of the Russian Federation [Электронный pecypc] // Official website. URL: www.ach.gov.ru/press_center/news/19560?sphrase $\mathrm{id}=1719995$ (дата обращения: 07.02.2016).

\section{S.M. Karanets}

\section{Characteristics of Library Services as Public Goods}

One of the important issues being actively discussed at the international and national conferences is determination of the economic essence of basic categories related to the library services. The article considers economic nature of library services as public goods, describes classification of library services (by the level of competitive performance of consumption and the principle of excludability; by the level of use of information and communication technologies; by the form of ownership of manufacturer), shows the active efforts of public libraries in the market of goods and services as real competitors to private entrepreneurs providing market services. The article considered the process of diversification, penetration into the Russian market of library services of publishers, archives and other organizations by means of creation of pure public goods. Special attention is paid to the goods temporarily not belonging to the pure public goods.

Key words: Goods, Public Goods, Local and Global Public Goods, the National Library of Russia in St. Petersburg.

Citation: Karanets S.M. Characteristics of Library Services as Public Goods, Bibliotekovedenie [Library and Information Science], 2016, vol. 1, no. 2, pp. 227-234. 


\section{About author}

Snezhana Mikhailovna Karanets, Russian Customs Academy St. Petersburg branch named after Vladivir Bobkov, Department of Economy of Customs Affairs, Candidate of Economic Sciences, Associate Professor

E-mail: richne2@ya.ru

52A, Sofiyskaya Str.,

St. Petersburg, 192241, Russia

\section{References}

1. Gorshkov Yu.A. Etika finansirovaniya resursnoi modernizatsii rossiiskikh bibliotek [Ethics of financing resource modernization of the Russian libraries], The website of the International Scientific and Practical Conference "Investing in libraries". Available at: http://www.nlr.ru/tus/161006/ (accessed 16.12.2015).

2. Elektronnaya biblioteka dissertatsii [Russian State Library Official website. Dissertation Collection]. Available at: http://diss.rsl.ru (accessed 16.12.2015).

3. Preiskurant no. 6/15 dopolnitel'nykh uslug RNB. Utverzhden Prikazom general'nogo direktora RNB ot 14 avgusta 2015 g. no. 305 [Prices no. 6/15 of additional services of the Russian National Library. Order of the General Director of the National Library of Russia 14 August 2015, no. 305], The website of the National Library of Russia. Available at: http://www.nlr.ru/ nlr/docs/price_gen/prices.pdf (accessed 16.12.2015).

4. Ivlieva T.N, Smolina E.V. Gosudarstvennoe investirovanie v sotsiokul'turnuyu sferu [Public investment in the production of public goods in the sociocultural sphere], The website of the National Library of Russia: International Scientific and Practical Conference "Investing in libraries". Available at: http://www.nlr.ru/tus/161006/Ivlieva_Smolina.htm (accessed 16.12.2015).

5. Karanets S.M. Fondy bibliotek v tsifrovuyu epokhu: traditsionnye i elektronnye resursy, komplektovanie, ispol'zovanie. Obzor materialov V Vserossiiskoi nauch.-prakt. konf. [Library collections in the digital age: traditional and electronic resources, acquisition, and use. Review of the 5th All-russian scientific and practical conference], Uchenye zapiski Sankt-Peterburgskogo filiala Rossiyskoy tamozhennoy academii [Scientific Letters of Russian Customs Academy St. Petersburg branch named after Vladivir Bobkov], 2015, no. 2(54), pp. 247-256.

6. The Ranking Web of World repositories, The Ranking Web of World repositories. Available at: http://repositories.webometrics.info/en/About_Us (accessed 17.12.2015).

7. Cousins J. Europeana Strategy 2020 - Making it work for the users and the data providers, Official website the Russian Association of Electronic Libraries. Available at: http://www.aselibrary.ru/video/conference43/conference436708/ (accessed 07.02.2016).

8. Website Pandora: Australia's Web Archive. Available at: http://pandora.nla.gov.au/statistics.html (accessed 11.02.2016).

9. Ivliev G.P. National Electronic Library - 2014/2015, Official website of the Russian Association of Electronic Libraries. Available at: http://www.aselibrary.ru/video/conference43/conference436448/;aselibrary.ru/ datadocs/Krim2015/Ivlev.pptx (accessed 11.02.2016).

10. London Library website. Available at: http://www. londonlibrary.co.uk/ (accessed 06.12.2015).

11. Website Accounts Chamber of the Russian Federation. Available at: www.ach.gov.ru/press_center/ news $/ 19560$ ?sphrase_id $=1719995$ (accessed 07.02.2016). 